\title{
Social capital and self-rated health: experiences from Makete district, Tanzania
}

GASTO FRUMENCE* and TUMAINI NYAMHANGA

Department of Development Studies, School of Public Health and Social Sciences, Muhimbili University of Health and Allied Sciences, Dar es Salaam, Tanzania

\begin{abstract}
Background: It is almost two decades since various research works started documenting the debate surrounding the role of social capital on individual health outcomes in different contexts. However, in Tanzania there is a dearth of empirical evidence showing how social capital influences health outcomes. The objective of this study was to investigate the links between individual social capital and self-rated health by selected socio-demographic factors.

Methods: We conducted a population-based cross-sectional study in Makete district in the south-western Tanzania. A semi-structured questionnaire was used to collect data using face to face interviews with the study participants. We collected information on individual structural social capita, which include memberships in organizations, giving social support, receiving social support and participation in voluntary activities. We also collected information on individual cognitive social capital including visiting neighbour, trusting neighbour, interaction with neighbour and ability to influence in decisions.

Results: A total of 862 individuals from four villages participated in the study with the mean age of 31.3 years. Factor analysis (using principal components analysis) with varimax determined four domains of structural social capital: participation in collective activities, giving social support, membership in formal and informal organizations and receiving social support (factor loadings: 0.65 to 0.55 ). Four domains of cognitive social capital were also identified: visiting a sick neighbour, trusting a neighbour, and interacting with neighbour and ability to influence decisions (Factors loadings: 0.78 to 0.52 ). The multivariable logistic regression analysis shows that individuals with access to medium and high levels of structural social capital were almost 2 and 3 times more likely to report good health than individuals with low social capital [OR 2.3 (Cl: 1.6-3.4)] and [OR $3.4(\mathrm{Cl}: 2.3-5.1)$, respectively.

Conclusion: Our study findings support the argument that high level of structural social capital has positive health outcomes in rural Tanzania' setting. Therefore, village leaders in particular and community members in general should promote social capital in their communities as one of the health interventions towards improving individual health.
\end{abstract}

Keywords: Social capital, self-rated health, Tanzania

\section{Introduction}

The definitions of social capital have been ranging from those focusing on resources gained because of one's involvement in the social networks (Lin, 2001) to the those covering social structures and resources obtained within these structures including reciprocity and trust (Harpham et al., 2002). There has been a debatable argument in several literature regarding whether social capital is a collective resource of communities or an individual property resulting from individual social networking. In his definition, Putnam (1993, 2000) described social capital encompassing characteristics of social organization including trust in others, civic participation and reciprocity, all of which facilitate cooperation among the community members for mutual benefits. Other scholars (Macinko \& Starfield, 2001) argue that social capital is regarded as collective resources because it involves people working together towards achieving collective common goals, otherwise it could not be realized by individual efforts. Social capital is also defined as the ability of individuals to control meagre resources through their involvement in social networks (Portes, 1998).

${ }^{*}$ Correspondence E-mail frumencegasto@yahoo.co.uk 
There are different distinctions of social capital. Recently the definition has distinguished social capital into structural and cognitive forms (Harpham et al., 2002). Structural social capital is about the extent to which individuals participate in various formal and informal social networks or groups' activities. Cognitive social capital includes intangible aspects resulting from members' involvement in networking including values, attitudes, beliefs, norms and reciprocity which can be valued as a resource emanating from members' interactions within the social networks. Other intangible aspects of cognitive social capital may include trust, perceptions of support and sharing (Krishna \& Uphoff, 1999; Uphoff \& Wijayaratna, 2000). Structural social capital can be further sub-classified into bonding, bridging and linking (Putnam, 2000; Woolcock, 2001). Bonding social capital constitutes social networks and relations based on homogeneous groups. It includes people who are closely linked through established networks in the form of both formal and informal groups, associations and clubs (Narayan \& Pritchett, 1999). As opposed to bonding social capital which involves closely and homogenous social groups, bridging social capital involves individuals, formal and informal organisations that cut across different communities and individuals (Narayan \& Pritchett, 1999). Linking social capital involves the relationships between individuals and groups, which do not constitute similar situations and are found in different communities. The linking social capital facilitates the members' access to more information, ideas and resources (Woolcock, 2001).

Recent years the public health arena has witnessed the debate about the contribution of social capital in improving health outcomes in different societies. For instance, Kawachi et al., (1997) found that collective social capital measured by the degree of mistrust, reciprocity and membership in voluntary in associations was correlated with lower mortality rates. In another study Hyyppä \& Mäki (2001) reported that individual social capital measured in terms of the number of groups' membership, friends and mistrust were all associated with self-rated health, which indicate that social capital may lead to individual health benefits. Several ways have been reported on how social capital may improve population's health including the dissemination of knowledge about health promotion, maintenance of norms that promote healthy behaviours through informal social command, supporting access to local services and facilities, and psychosocial processes providing mutual respect in the communities or societies (Kawachi, 2000). Other scholars emphasize that social capital make possible healthy behaviours because members of the social networks adopt behaviours demonstrated by role models within the networks (Rogers, 1983; Erickson, 1988).

Generally, there is rich literature on the contribution of social capital on population health in developed countries. However, there is less documentation from the developing countries particularly in Sub-Saharan African including Tanzania regarding the link between social capital and population health. The aim of this study was to investigate the links between individual social capital and self-rated health by selected socio-demographic factors in the rural setting in Tanzania. In this study, we have adopted Putnam's (2000) definition of social capital, encompassing both structural and cognitive social capital and emphasizing that social capital involves networks, norms and trust.

\section{Materials and Methods}

\section{Study design and data collection}

This was a cross-sectional study, which used data from a randomly selected people living in Makete rural district, situated in Njombe region in the Southern part of Tanzania. The sample size was determined using a formula developed by Frank- Nachmias \& Nachmias (1996): $\quad \mathrm{N}=\mathrm{S} 2$ /(S.E)2; Where $\mathrm{N}=$ the desired sample size, $\mathrm{S}=$ standard deviation of the variables under study, $\mathrm{S}$.E=standard error (error margin). For the purpose of this study, a standard deviation of 1.2 was assumed. In order to attain a sample size that could generate reliable estimates of the population 
parameters, the standard error was set at 4\% (Olukorede \& Isiugo-Abanihe, 2012). Therefore, the sample size $\mathrm{N}=(1.2) 2 /(0.04) 2=900$ individuals. A questionnaire was administered to randomly selected individuals.

A multistage sampling strategy was used to select villages from which the study participants were recruited. Two wards were randomly selected and two villages were randomly selected within each ward. Upon reaching each selected village a sampling frame was established by getting a list of households from the village executive officer. The total number of households was divided by the sample size per village to obtain the sampling interval " $n$ ". Every $n^{\text {th }}$ household was randomly picked until the required sample size was reached.

\section{Measurement of self-rated health (outcome variable)}

The primary outcome measure was self-reported general health status, in response to the question: How do you perceive your overall health during this last year? Would you say it is very good, rather good, fair, rather poor or poor? These responses were collapsed into a dichotomous outcome. Very good, rather good and fair were grouped together as good health whereas rather poor and poor were grouped together as poor health.

\section{Measurement of individual social capital}

For measuring individual social capital, we applied factor analysis (using principal components analysis) with varimax rotation to determine the underlying items and their related dimensions. The first two components accounted for $48.5 \%$ of all the observed variance and were retained because they obtained an eigenvalue $>1$. The first component - participation in collective activities (0.65), giving social support (0.62), membership in formal and informal organizations (0.60) and receiving social support (0.55) - had high loadings. All factors in this component were categorized as structural indicators of individual social capital because they showed that membership in formal and informal organizations (networking) not only results into giving members opportunity to participate in collective activities but also enhances reciprocal relations in the community. In the second component, visiting a sick neighbour (0.78), trusting a neighbour (0.66), interacting with neighbour (0.63) and ability to influence decisions (0.52) had high loadings. Visiting and trusting neighbours had the highest loadings in the second component showing their importance in measuring individual social capital. All factors in the second components belong to the cognitive part of individual social capital. This factor analysis helped us calculate factor scores for structural and cognitive social capital for each individual. We also divided the generated factor scores/index into three equal quintiles to create three levels of structural and cognitive social capital: low, medium and high.

\section{Data analysis}

SPSS was used for data entry and analysis. We performed bivariate and multivariable logistic regression analyses to estimate the impact of structural and cognitive social capital on self-rated health taking account to possible confounding variables. Odds ratios (OR) and 95\% confidence intervals $(\mathrm{Cl})$ were calculated and only variables significant in the bivariate analysis were entered into the multivariable analysis.

\section{Ethical considerations}

Muhimbili University of Health and Allied Sciences Research and Publication Committee granted ethical clearance to conduct the study. Permission to conduct the study was also obtained from Njombe Regional and Makete district authorities as well as ward and village leadership in the study area. Individual informed verbal consent was obtained from all participants and they were also informed about anonymity and confidentiality issues. 


\section{Results}

\section{Descriptive statistics}

Out of the 900 randomly selected individuals, 862 (96\%) agreed to be interviewed from the four selected villages in the district. Majority of the respondents were aged between $24-34$ years (57\% females and $43 \%$ males). Most of the study respondents (84\%) had primary level of education. Only $16 \%$ of the 862 study participants claimed that they were unemployed. The rest were engaged in productive activities farming activities (47\% females and $53 \%$ males). Regarding features of structural social capital, most of the participants $68 \%$ (55\% females and $45 \%$ males) were actively participating in both formal and informal organizations. Almost all participants were active in cognitive social capital including visiting and trusting their neighbours, $57 \%$ for females compared to $43 \%$ for males. A higher percentage of women $(56 \%)$ rated their health as good compared to men $44 \%$ (Table 1 ).

Table 1. Socio-demographic characteristics, cognitive and structural social capital (SC), and the main outcome variable self-rated health by sex

\begin{tabular}{|c|c|c|c|c|c|c|c|}
\hline \multirow[t]{2}{*}{ Variable } & \multirow[t]{2}{*}{ Response } & \multicolumn{2}{|c|}{ Females $(n=490)$} & \multicolumn{2}{|c|}{ Males $(n=372)$} & \multicolumn{2}{|l|}{ Total } \\
\hline & & No & $\%$ & No & $\%$ & No & $\%$ \\
\hline \multirow[t]{4}{*}{ Age } & $15-24$ & 140 & 56 & 112 & 44 & 252 & 29 \\
\hline & $25-34$ & 182 & 57 & 138 & 43 & 320 & 37 \\
\hline & $35-44$ & 96 & 53 & 84 & 47 & 180 & 21 \\
\hline & $45-60$ & 72 & 65 & 38 & 35 & 110 & 13 \\
\hline \multirow[t]{4}{*}{ Occupation } & Peasant & 112 & 47 & 124 & 53 & 236 & 27 \\
\hline & Professional & 198 & 77 & 60 & 23 & 258 & 30 \\
\hline & Business & 88 & 39 & 140 & 61 & 228 & 27 \\
\hline & Unemployed & 92 & 66 & 48 & 34 & 140 & 16 \\
\hline \multirow[t]{3}{*}{ Marital status } & Single & 194 & 61 & 124 & 39 & 318 & 37 \\
\hline & Married mono-polygamous & 256 & 58 & 182 & 42 & 438 & 51 \\
\hline & $\begin{array}{l}\text { Separated/ } \\
\text { Divorced/widowed }\end{array}$ & 32 & 33 & 66 & 67 & 98 & 12 \\
\hline \multirow[t]{3}{*}{ Religion } & Christianity & 486 & 57 & 368 & 43 & 854 & 99 \\
\hline & Muslim & - & - & 4 & 100 & 4 & 0.5 \\
\hline & Traditional & 4 & 100 & - & - & 4 & 0.5 \\
\hline \multirow[t]{3}{*}{ Education } & None & 12 & 30 & 28 & 70 & 40 & 5 \\
\hline & Primary & 394 & 55 & 322 & 45 & 726 & 84 \\
\hline & Secondary+ & 76 & 79 & 20 & 21 & 96 & 11 \\
\hline \multirow{5}{*}{$\begin{array}{l}\text { Individual } \\
\text { structural SC }\end{array}$} & Member in organization & 318 & 55 & & & 582 & 68 \\
\hline & & & & 264 & 45 & & \\
\hline & Giving social support & 262 & 51 & 248 & 49 & 510 & 59 \\
\hline & Receiving social support & 438 & 57 & 324 & 43 & 762 & 88 \\
\hline & $\begin{array}{l}\text { Participation in voluntary } \\
\text { activities }\end{array}$ & 274 & 56 & 214 & 44 & 488 & 57 \\
\hline & Visiting neighbour & & 57 & 348 & 43 & 814 & 94 \\
\hline \multirow{4}{*}{ cognitive SC } & & 466 & & & & 8,8 & \\
\hline & Trusting neighbour & 486 & 57 & 362 & 43 & $\begin{array}{l}848 \\
8-8\end{array}$ & 98 \\
\hline & Interaction with neighbour & 490 & 57 & 368 & 43 & 858 & 99 \\
\hline & $\begin{array}{l}\text { Ability to influence in } \\
\text { decision }\end{array}$ & 366 & 62 & 228 & 38 & 594 & 69 \\
\hline Outcome variable & Self-rated health & 264 & 56 & 204 & 44 & 468 & 54 \\
\hline
\end{tabular}

Individuals aged 25-34 years and 35-44 years significantly elevated the likelihood for reporting good health compared to individuals aging 15-24 and 45-60 years old. In multivariable regression analysis individuals who were employed as peasants, professional or business were $3.9,4.3$ and 
3.9 times more likely to report good health than those who were unemployed, OR 3.4 (Cl:1.8-6.2); OR 4.3 ( $\mathrm{Cl}: 2.4-7.6)$ and $\mathrm{OR} 3.9$ ( $\mathrm{Cl}: 2.2-7.1)$, respectively. The higher the level of education, the increased odds of reporting good health, OR $3.7(\mathrm{Cl}: 1.5-8.9)$ and $\mathrm{OR} 5.6(\mathrm{Cl}: 2.0-15.6)$ for primary level of education and secondary and above level of education respectively (Table 2).

\section{The association between individual structural and cognitive social capital and self-rated health}

Access to structural social capital (participation in collective activities, giving social support, membership in formal and informal organizations and receiving social support) significantly increased the odds for good self-rated health. In bivariate analysis, individuals with access to medium and high levels of structural social capital were 2.6 ( $\mathrm{Cl}$ : 1.8-3.6) and 4.6 ( $\mathrm{Cl}$ : 3.2-6.6) times likely to report good health than those with low structural social capital. After controlling for confounders such as sex, age, occupation, marital status, religion and level of education, the multivariable logistic regression analysis shows that individuals with access to medium and high levels of structural social capital were almost 2 and 3 times more likely to report good health than individuals with low social capital, OR 2.3 (Cl: 1.6-3.4) and OR 3.4 (Cl: 2.3-5.1), respectively. In both bivariate and multivariable logistic regression analyses, access to the cognitive forms of social capital (i.e., trusting neighbours, reciprocity norms and ability to influence decision making), was not associated with reporting good health compared to the structural social capital (Table 2).

Table 2. Bivariate and multivariable logistic regression analyses of the impact of socio-demographic characteristics and structural and cognitive social capital (SC) on self-rated health

\begin{tabular}{|c|c|c|c|c|c|c|c|}
\hline \multirow[t]{2}{*}{ Variable } & \multirow[t]{2}{*}{ Response } & \multicolumn{2}{|c|}{ Self-rated health } & \multicolumn{2}{|c|}{ Bivariate analysis } & \multicolumn{2}{|c|}{$\begin{array}{l}\text { Multivariable } \\
\text { logistic regression }\end{array}$} \\
\hline & & Good & Poor & OR & $95 \% \mathrm{Cl}$ & OR & $95 \% \mathrm{Cl}$ \\
\hline \multirow[t]{2}{*}{ Sex } & Female & 264 & 226 & 1 & & 1 & \\
\hline & Male & 204 & 168 & 1.04 & $0.80-1.4$ & 0.90 & $0.65-1.3$ \\
\hline \multirow[t]{4}{*}{ Age (years) } & $15-24$ & 106 & 146 & 1 & & 1 & \\
\hline & $25-34$ & 196 & 124 & 2.2 & $1.6-3.0$ & 1.5 & $0.96-2.2$ \\
\hline & $35-44$ & 110 & 70 & 2.2 & $1.5-3.2$ & 1.3 & $0.77-2.1$ \\
\hline & $45-60$ & 45 & 54 & 1.4 & $0.9-2.2$ & 0.9 & $0.56-1.7$ \\
\hline \multirow[t]{4}{*}{ Occupation } & Unemployed & 44 & 96 & 1 & & 1 & \\
\hline & Peasant & 122 & 114 & 2.3 & $1.5-3.6$ & 3.4 & $1.8-6.2$ \\
\hline & Professional & 154 & 104 & 3.2 & $2.1-4.9$ & $4 \cdot 3$ & $2.4-7.6$ \\
\hline & Business & 148 & 80 & 4.0 & $2.6-6.3$ & 3.9 & $2.2-7.1$ \\
\hline \multirow[t]{3}{*}{ Marital status } & Single & 152 & 166 & 1 & & 1 & $0.80-1.7$ \\
\hline & $\begin{array}{l}\text { Married mono- } \\
\text { polygamous }\end{array}$ & 260 & 178 & 1.6 & $1.2-2.1$ & 1.2 & $0.71-2.3$ \\
\hline & $\begin{array}{l}\text { Separated/divorced } \\
\text { /widowed }\end{array}$ & 54 & 44 & 1.3 & $0.85-2.1$ & 1.3 & \\
\hline \multirow[t]{2}{*}{ Religion } & Christian & 388 & 327 & 1 & & 1 & \\
\hline & Muslim & 80 & 67 & 1.0 & $0.71-1.4$ & 1.2 & $0.78-1.8$ \\
\hline \multirow[t]{3}{*}{ Education } & None & 8 & 32 & 1 & & 1 & \\
\hline & Primary & 408 & 308 & $5 \cdot 3$ & $2.4-11.6$ & 3.7 & $1.5-8.9$ \\
\hline & Secondary+ & 46 & 50 & 3.7 & $1.5-8.8$ & 5.6 & $2.0-15.6$ \\
\hline \multirow[t]{3}{*}{ Structural SC } & Low & 100 & 188 & 1 & & 1 & \\
\hline & Medium & 166 & 122 & 2.6 & $1.8-3.6$ & 2.3 & $1.6-3.4$ \\
\hline & High & 202 & 82 & 4.6 & $3.2-6.6$ & 3.4 & $2.3-5.1$ \\
\hline \multirow[t]{3}{*}{ Cognitive SC } & Low & 184 & 100 & 1 & & 1 & \\
\hline & Medium & 136 & 150 & 0.49 & $0.35-0.69$ & 0.32 & $0.21-0.48$ \\
\hline & High & 142 & 142 & 0.53 & $0.39-0.76$ & 0.39 & $0.26-0.59$ \\
\hline
\end{tabular}




\section{Discussion}

This study has illustrated that individuals who were engaging in some economic activities such as farming, business or employed as professionals reported good health compared to individuals who were not engaged in any activity (unemployed). Furthermore, high level of education also increased the likelihood of reporting good health when compared to individuals with low level of education. This means that individuals who are educated and active in economic activities can easily interact with their colleagues through different networks or social groups. Such interactions may help them to access health related information, which in turn may help them to improve their health when compared to those who are not socially and economically active. A number of mechanisms through which social capital can be linked to health outcomes have been elucidated particularly from developed countries. Some scholars argue that socially isolated individuals have limited access to social resources such as emotional support and information, which increases the risk of having poor health outcomes (Berkman \& Syme, 1979; House et al., 1988; Kawachi et al., 1996). People who are socially isolated are considered to be at risk of poor health outcomes because they are likely to live in areas with diminished social capital due to the fact that such communities may not provide enough opportunities for community members to form local networks (Wacquant \& Wilson, 1989; Sampson, 2016). A recent study in Ghana revealed that individuals who were active in social interactions were more likely to join health insurance scheme, which in turn improved their health status (Fenenga et al., 2015).

In this study both the bivariate and multivariable analyses illustrated that access to structural social capital measured by participation in collective activities, giving social support, membership in formal and informal organizations and receiving social support was associated with self-reported good health. A study in South Africa on the relationship between social capital and self-rated health reported that structural social capital, measured by individual's membership to community service groups was beneficial to self-rated health (Lau \& Ataguba, 2015). In developed countries, a number of studies have shown that structural social capital in the form of participation and interactions with friends, relatives and networks were associated with better self-rated health (Verhaeghe et al., 2012).

In this study, cognitive forms of social capital, i.e. trusting neighbours, reciprocity norms and ability to influence decision making, was not associated with reporting good health. Similarly, in South Africa and Japan reciprocity was not associated with good self-rated health (Ota, 2013; Lau \& Ataguba, 2015). Our findings are contrary to findings from other studies in Chile (Sapag et al., 2008) and England (Verhaeghe \& Tampubolon, 2012), which showed that cognitive forms of social capital measured by neighbourhood social cohesion, personalized trust and reciprocity, was associated with higher self-rated health. The unexpected inverse association between cognitive forms of social capital and better health has been reported elsewhere (Ota, 2013). It is possible that the existing low trust and poor reciprocal relations in rural Tanzania is partly a result of existing poverty condition, which cannot be easily associated with good health among rural dwellers.

One of the limitations of this study is that it employed the cross sectional study design, through which causal inference cannot be made. The study is also subjected to bias because it included perceptions of social capital and health issues which were self-reported by the study participants. Nevertheless, the study provides useful information on how social capital influences health outcomes in Tanzania.

Our study supports the argument that high level of structural social capital has positive health outcomes. Therefore, it is important for all key stakeholders including community members to promote social capital as one way of improving their health. Village leaders and community members should consider promoting social capital as one of the strategies towards improving individuals' health. Improving community members' participation in formal and 
informal groups and collective activities as well as giving each other social support may improve health.

\section{Competing interest}

None

\section{References}

Berkman, L.F. \& Syme, S.S. (1979) Social networks, host resistance and mortality: a nine-year follow-up study of Alameda County residents. American Journal of Epidemiology 109: 186204.

Erickson, B. (1988) The relational basis of attitudes. In: S.D. Wellman, B. \& Berkowitz (Ed.), Social Structures: A Network Approach (pp. 99-128). Cambridge University Press.

Fenenga, C.J., Nketiah-amponsah, E., Ogink, A., Arhinful, D.K., Poortinga, W. \& Hutter, I. (2015) Social capital and active membership in the Ghana National Health Insurance Scheme - a mixed method study. International Journal for Equity in Health 1-12. Article. http://doi.org/10.1186/s12939-015-0239.

Harpham, T., Grant, E. \& Thomas, E. (2002) Measuring social capital within health surveys: key issues. Health Policy and Planning 17: 106-111.

House, J.S., Landis, K. R., \& Umberson, D. (1988). Social relationships and health. Science. misc. http://doi.org/10.1126/science.3399889

Hyyppä, M. T., \& Mäki, J. (2001). Individual-level relationships between social capital and selfrated health in a bilingual community. Preventive Medicine, 32(2), 148-155. article. http://doi.org/10.1006/pmed.2000.0782

Kawachi, I., Colditz, G.A., Ascherio, A., Rimm, E.B., Giovannucci, E., Stampfer, M.J. \& Willett, W.C. (1996) A prospective study of social networks in relation to total mortality and cardiovascular disease in men in the USA. Journal Epidemiology Community Health 50: 245251.

Kawachi, I., Kennedy, B.P., Lochner, K. \& Prothrow-Stith, D. (1997) Social capital, income inequality, and mortality. American Journal of Public Health 87: 1491-1498.

Kawachi, I.B.L. (2000). Social cohesion, social capital, and health. In B. LF \& K. I (Eds.), Social Epidemiology (p. 174-190.). New York: Oxford University Press.

Krishna, A. \& Uphoff, N. (1999) Mapping and Measuring Social Capital : A Conceptual and Empirical Study of Collective Action for Conserving and Developing Watersheds in Rajasthan, India. Social Indicators Research.

Lau, Y.K. \& Ataguba, J.E. (2015) Investigating the relationship between self-rated health and social capital in South Africa: a multilevel panel data analysis. BMC Public Health 15(1): 266.

Lin, N. (2001). Social Capital: A Theory of Social Structure and Action. book, New York: Cambridge University Press.

Macinko, J. \& Starfield, B. (2001) The utility of social capital in research on health determinants. The Milbank Quarterly 79: 387--427.

Narayan, D. \& Pritchett, L. (1999) Cents and Sociability: Household Income and Social Capital in Rural Tanzania. World Bank 47: 871-897.

Olukorede, W.E. \& Isiugo-Abanihe, U.C. (2012) Correlates of Adequacy of Retirement Benefits Among the Older Persons in Nigeria. European Scientific Journal 8: $1857-7881$

Ota, H. (2013) Ota social capital and SRH in Japan. Japanese JOurnal of Public Health, 61(2), 71-85. article.

Portes, A. (1998) Social capital: Its origins and applications in modern sociology. Annual Review of Sociology 24: 1-24. 
Putnam, R.D. (1993) Making democracy work: Civic traditions in modern Italy. book, Princeton, N.J.: Princeton University Press.

Putnam, R. D. (2000) Bowling alone. The collapse and revival of American community. book, New York: Simon \& Schuster.

Rogers, E. (1983). Diffusion of Innovations. New York: Free Press.

Sampson, R.J. (2016) Local Friendship Ties and Community Attachment in Mass Society: A Multilevel Systemic Model Author ( $\mathrm{s}$ ): Robert J . Sampson Source : American Sociological Review, Vol . 53, No . 5 ( Oct ., 1988 ), pp . 766-779 Published by : American Sociological Asso, 53(5), 766-779. article.

Sapag, J. C., Aracena, M., Villarroel, L., Poblete, F., Berrocal, C., Hoyos, R., ... Kawachi, I. (2008). Social capital and self-rated health in urban low income neighbourhoods in Chile. Journal of Epidemiology and Community Health, 62(9), 790-792. article. http://doi.org/10.1136/jech.2006.052993

Uphoff, N., \& Wijayaratna, C. M. (2000). Demonstrated benefits from social capital: The productivity of farmer organizations in Gal Oya, Sri Lanka. World Development, 28(11), 18751890. http://doi.org/10.1016/S0305-750X(00)00063-2

Verhaeghe, P. P., Pattyn, E., Bracke, P., Verhaeghe, M., \& Van de Putte, B. (2012). The association between network social capital and self-rated health: Pouring old wine in new bottles? Health and Place, 18(2), 358e365.

Verhaeghe, P. P., \& Tampubolon, G. (2012). Individual social capital, neighbourhood deprivation, and self-rated health in England. Social Science and Medicine, 75(2), 349-357. article. http://doi.org/10.1016/j.socscimed.2012.02.057

Wacquant J.D and Wilson W. J. (1989). The Cost of Racial and Class Exclusion in the Inner City. The Annals of the American Academy of Political and Social Science, 501, 8-25. article.

Woolcock, M. (2001). The place of social capital in understanding social and economic outcomes. Canadian Journal of Policy, 2, 1-17. article. 